\title{
Política e saúde coletiva: reflexão sobre a produção científica (1976-1992)
}

\author{
Policy and Collective Health: a reflection \\ on scientific production (1976-1992)
}

Luciene Burlandy 1

Regina Celede A. Bodstein 2

\footnotetext{
1 Departamento de Nutrição Social, Faculdade de Nutrição, Universidade Federal Fluminense. Rua São Paulo 30, 4 o andar, Niterói, RJ, 24020-120, Brasil. 2 Departamento de Ciências Sociais, Escola Nacional de Saúde Pública,

Fundação Oswaldo Cruz. Rua Leopoldo Bulhões 1480, sala 916, Rio de Janeiro, RJ 21041-210, Brasil. bodstein@ensp.fiocruz.br
}

A bstract This study systematizes the theoretical and conceptual foundations in the field of Collective Health that have provided the basis for scientific production in the heal th policy area. The primary research source is the literature produced in two different contexts in this field, i.e., that of its emergence per se and the scope of the so-called Health Reform. The authors highlight the main concepts and theoretical references from the social sciences used in analyzing the heal th policy theme, identifying analytical distinctions, concepts pertaining to policy, the state, and health, and changes in the central categories from the vari ous studies. Their analysi s of this history indicates a reshaping of the theoretical frame of reference, giving greater flexibility to the structural determinism and macrosocial approach characterizing a major portion of academic production in the context from which the field emerged and thereby questioning the hegemony of the Marxist paradigm. In relation to more recent production, the authors emphasize the incorporation of new analytical references, thus providing greater complexity to the relationship between the social sciences and the field of Collective Health.

Key words Public Health; Health Policy; Social Sciences

Resumo O presente estudo sistematiza os fundamentos teórico-conceituais do campo da Saúde Coletiva que embasaram a produção científica na área de Políticas de Saúde no Brasil. Utiliza como fonte primária de pesquisa a literatura produzi da em duas conjunturas distintas deste campo disci plinar: em seu contexto de emergência e no âmbi to da chamada Reforma Sanitária. São destacados os principais concei tos e referenciais teóricos das Ciências Soci ais utilizados peI os autores na problematização da temática das Políticas de Saúde, identificando distinções analíticas, concepções de Política, Estado e Saúde bem como mudanças em torno das categorias que adquirem centrali dade nas obras. A análi se desta traj etória aponta para um redimensionamento do referencial teórico, no sentido de flexibilizar o determinismo estrutural e a abordagem macrosocial que marcou grande parte da produção acadêmica no contexto de emergência do campo, relati vizando a hegemonia do paradigma marxista. Na produção mais recente, destacase a incorporação de novos referenciais analíticos, compl exificando a rel ação entre as ciências sociais e o campo da Saúde Col etiva.

Palavras-chave Saúde Pública; Políticas de Saúde; Ciências Sociais 


\section{Introdução}

O debate atual travado pela comunidade científica nos diferentes campos disciplinares vêm apontando limites e possibilidades dos paradigmas que nortearam a produção de conhecimento nas últimas décadas. A dinâmica deste processo no campo sociológico é particularmente interessante se pensarmos nos reflexos que traz para a aplicação das Ciências Sociais em Saúde e particularmente para área da saúde coletiva, onde questionamentos em torno da propriedade analítica dos diferentes referenciais teóricos vêm ocupando o debate acadêmico (Costa \& Costa, 1990; Bodstein, 1992; Teixeira, 1992; Canesqui, 1995).

A formação da Saúde Coletiva enquanto um campo científico envolve tanto a consolidação de uma rede de instituições de pesquisa e ensino quanto a construção de uma base conceitual-metodológica que fundamenta as investigações e confere identidade teórico/ temática a sua produção (Ribeiro, 1991). Este processo é determinado por motivações de cunho fundamentalmente intelectual/científico dos agentes envolvidos e por fatores referentes à dimensão político-social que os situa (Bourdieu, 1976).

Dentro desta perspectiva, nosso objetivo é identificar os principais referenciais teóricoconceituais que foram adotados pela produção científica sobre política no campo da Saúde Coletiva no Brasil. Para tal, analisamos obras clássicas de relevância para a formação do pensamento teórico e prático neste campo científico, compreendendo este processo também a partir do relato oral de seus autores, por sua vez ligados a diferentes instituições acadêmicas de referência para esta área. Este conjunto de obras, datadas de 1976 a 1992, constitui bibliográfica básica, de citação recorrente na produção sobre política no campo da Saúde Coletiva. Esta delimitação cronológica visa distinguir a produção em dois momentos: a conjuntura de emergência do campo e a chamada Reforma Sanitária, no contexto imediatamente posterior à formalização constitucional de seus princípios no SUS. Para efeitos analíticos, destacamos mudanças em torno de categorias que adquirem centralidade nesta produção, tais como: Saúde, Estado e Políticas Sociais.

\section{A constituição do campo} da saúde coletiva

A temática das Ciências Sociais em Saúde, segundo Nunes (1985), tem origem relativamente recente nos países latino americanos, situada em torno das três últimas décadas. Esta preocupação tardia com a sistematização das questões sociais na área de saúde é atribuída, dentre outros fatores, ao grande avanço da bacteriologia e à hegemonia da vertente biologicista nas ciências da saúde.

A relação entre estes dois campos disciplinares - Ciências Sociais e Saúde - é marcada por diferenças tanto em termo de concepções teórico-metodológicas quanto em termos de práticas sociais entre os profissionais envolvidos (cientistas sociais e profissionais da saúde) (Garcia, 1989).

De um lado, as Ciências Sociais e sua preocupação fundamentalmente analítica, de outro, a medicina de cunho fortemente tecnicista e pragmático, pautada sobre um modelo biologicista. Essas diferenças de concepções e práticas certamente marcam toda a trajetória de construção do pensamento no campo das Ciências Sociais em Saúde. Em que pese a diversidade de enfoques, segundo Nunes (1985), destaca-se a hegemonia de três abordagens teóricas: a antropológica culturalista, na década de 50, a fenomenológica, predominante na década de 60, e por fim, a histórico estrutural que fundamenta grande parte da produção na década de 70.

Ressalta-se que a opção por um enfoque analítico denominado de histórico estrutural, imprime na década de 70 uma certa identidade teórico-temática à produção (Almeida \& Burlandy, 1991). As análises da relação saúde e sociedade feitas até então são denominadas sob o termo comum de "ciências da conduta", um conceito neutro como aponta Mercer (1985) que caracteriza a posição inicial de aparente imparcialidade política assumida pelas ciências sociais na saúde.

É na reunião de Cuenca, Equador, em 1972, que são apontadas as limitações deste enfoque e se estabelece uma espécie de "acordo político-intelectual" em torno de um novo marco teórico de análise e reflexão sobre a questão sanitária, no sentido de compreendê-la a partir das relações com a estrutura política e econômica. Dessa forma, o marxismo (um tema proibido no contexto da ditadura) torna-se a corrente hegemônica na investigação em saúde na década de 70 sob a denominação de "Materialismo Histórico Estrutural" (Mercer,1985). A incorporação desta matriz teórica não é, no en- 
tanto, homogênea. Na realidade o legado de Marx tem sido objeto de períodicas releituras que podem ser identificadas na produção no campo da Saúde Coletiva. Partimos da hipótese de que o marxismo incorporado a produção científica em saúde nos anos 70 corresponde fundamentalmente à abordagem determinista-estruturalista, como ressalta Mercer (1985). Com base neste marco teórico-conceitual, constrói-se uma análise estrutural da questão saúde a partir de sua inserção na sociedade capitalista vis-à-vis um determinado sistema de classes. Em termos conjunturais, relaciona-se a problemática da saúde coletiva ao sistema político-econômico concentrador de renda e ao regime político autoritário. O conceito chave então elaborado, no sentido de expressar esta articulação saúde/ sociedade, é o de "organização social da prática médica", definido por Nogueira como "o conjunto estruturado e instituci onal izado das relações sociais- políticas econômicas e ideológicas - próprias de um tipo de prática médica" (Nogueira, 1983 apud Teixeira, 1985:91).

Como parte deste movimento, mas mantendo certa autonomia, desenvolve-se uma nova ótica de análise no campo da epidemiologia, a chamada epidemiologia social, centrada em uma concepção que enfatiza o caráter social do processo saúde-doença, utilizando como categoria analítica chave o conceito de "determinação social da doença".

\section{A produção acadêmica no campo das políticas de saúde}

\section{Contexto político e a produção teórica}

A Saúde Coletiva enquanto campo específico de produção de conhecimento no país configura-se em meados da década de 70, numa conjuntura permeada por acirrados enfrentamentos político-ideológicos (Ribeiro, 1991). O primeiro deles refere-se a uma confrontação política que gera uma unidade interna ao próprio campo. Trata-se da militância política que caracteriza grande parte dos profissionais desta área que, conjunturalmente se unem em oposição ao Estado autoritário/repressor e ao que se concebia então como um modelo de atenção à saú de excludente e discriminatório. Isto se reflete na conformação de seu tema, objeto e método de estudo (Fiori, 1978). Este movimento de oposição política e ideológica tem inicialmente um forte caráter de denúncia decorrente da constatação de que a lógica perversa do capitalismo atingiu a medicina.
Além deste embate político mais amplo, um segundo confronto se dá no plano teórico, em oposição a uma área de conhecimento já então amplamente consagrada: a medicina clínica de enfoque biologicista bem como seus desdobramentos na Saúde Pública. Buscando sua especificidade, a Saúde Coletiva propõe, desde seu início, a compreensão da integralidade do indivíduo e, portanto, do sujeito/ator social. Inserindo este indivíduo no seu contexto social, busca as manifestações do processo saúde-doença (também determinado socialmente) em seu organismo. Desta forma, procura ultrapassar a hegemonia da análise médicocurativista e o paradigma biologicista em saúde. De igual modo, este movimento de criar uma identidade própria ao campo implica a revisão de determinadas práticas de Saúde Pública, que não relacionam saúde e determinantes estruturais, mantendo-se nos limites do paradigma biologicista, ainda que retraduzido sob a perspectiva coletiva (Birman, 1991).

Este confronto é, não apenas conceitual mas marcadamente político-ideológico, uma vez que, através da exclusão de determinados paradigmas, atores, práticas e teorias afirmamse as bases que fundamentam a unidade teórico-política do campo. Em contrapartida a uma privatização da medicina, a Saúde Coletiva levanta a bandeira da responsabilidade estatal e, portanto, das políticas governamentais. Por outro lado, contra um sistema capitalista perverso, que faz da saúde objeto de lucro, discriminação e exclusão por critérios de mercado, defende-se o modelo socialista, em sua potencialidade de equacionar desigualdades através de políticas sociais mais equânimes e eficientes (Novaes, 1988).

A especificidade deste novo campo de produção científica é assim, em grande parte, fruto dessa tentativa de construção de um quadro conceitual-metodológico fortemente influenciado pelo materialismo histórico, então dominante no campo das ciências sociais no Brasil. A análise desse objeto, situado na interface entre dois campos de conhecimento - ciências sociais e saúde, engendrou duas grandes linhas temáticas: a epidemiologia social e uma outra comumente identificada como Políticas de Saúde, Organização dos Serviços e das Práticas de Saúde, sobre a qual nos deteremos mais especificamente. 
A produção sob a perspectiva

do Materialismo Histórico

Ainda que seguindo perspectivas distintas na abordagem da temática das políticas de saúde, as análises produzidas na conjuntura dos anos 70 têm um pano de fundo comum: desvendar os mecanismos e estratégias (econômicas, políticas e ideológicas) de reprodução do modo de produção capitalista e as formas de articulação e inserção das políticas de saúde no processo de acumulação de capital. O instrumental teórico, bem como o recorte temático e metodológico, é basicamente inspirado no marxismo.

As políticas de saúde são compreendidas na especificidade de uma sociedade capitalista, tendo como referência o Estado enquanto agente privilegiado destas políticas. Neste sentido o objetivo central é analisar as diferentes formas através das quais o Estado, seus apareIhos, suas políticas e instituições garantem as condições de reprodução do capitalismo e, portanto, dos interesses das classes dominantes. Esta referência direta ao âmbito estatal tem também uma relação com as próprias "funções" das políticas de saúde: o controle político e o controle econômico exercido pelo Estado.

Ressalta-se por um lado a tarefa reguladora que a medicina assume frente à vida privada, em particular aos estratos inferiores da sociedade, e por outro, o papel do Estado de imprimir através das políticas sociais um processo mais amplo de controle dos antagonismos de classe (Donnangelo \& Pereira, 1976; Oliveira \& Teixeira, 1989).

O efeito especificamente político de controle se expressa no fato de as políticas de saúde destinarem-se prioritariamente aos trabaIhadores, visando discipliná-los e adaptá-los às relações sócio-econômicas vigentes. Por outro Iado, o controle econômico exercido pelo Estado através dessas políticas traduz-se na garantia das condições mínimas de reprodução da força de trabalho. As instituições médicas desempenham assim um papel importante para o sistema econômico ao possibilitar a reparação e reprodução do trabal hador. Visam controlar ou prevenir doenças, principalmente aquelas que atuam como elemento perturbador do desenvolvimento econômico (Luz, 1986).

A compreensão das políticas sociais, nestas diferentes análises, tem relação direta com a concepção de estado e sociedade assumida pelos autores, que varia em torno de três concepções básicas: uma perspectiva que concebe o Estado a serviço do Capital, onde as funções bási cas das políticas de saúde são acumulação e controle de classe (Braga \& Paula, 1986); uma visão do Estado enquanto condensação de uma relação de forças, onde as políticas sociais são compreendidas não só como instrumentos de acumulação, mas também de legitimação e garantia de um mínimo de consenso político para a o exercício da dominação, (Oliveira \& Teixeira, 1989); e o conceito de Estado Ampliado que se confunde com a própria sociedade, onde as políticas de saúde constituem parte de uma estratégia de implantação de hegemonia institucional. Na medida em que são compreendidas como parte de uma estratégia de hegemonia, mutável face à conjuntura e à correlação de forças vigente, estas políticas e instituições tornam-se palco de luta de interesses contraditórios, expressando projetos políticos mais amplos. Esta abordagem assimila uma matriz analítica praticamente nova entre nós centrada na identificação dos chamados micropoderes presentes nas relações cotidianas, que foram negligenciados nas análises macro-estruturais até então predominantes (Luz, 1986).

Embora a questão da determinação econômica em última instância seja uma perspectiva comum nestas obras, podemos identificar autores como Donnangel o e Luz que reforçam a prática política como potencialmente transformadora das relações de produção. Apenas afirmar que as políticas sociais têm o efeito de reproduzir a estrutura vigente é restringir a análise a uma constatação bastante generalizante e pouco enriquecedora (Donnangelo \& Pereira, 1976; Luz, 1986).

\section{A questão da prática médica}

É interessante notar como a prática médica e a medicina em si são tematizadas, já que esta abordagem influencia boa parte da produção teórica na Saúde Coletiva. Cabe aqui ressaltar que Donnangelo e Pereira são considerados os precursores, por focalizarem o caráter histórico da medicina e seu movimento crescente de politização, analisando sua prática antes de tudo enquanto uma prática social. Suas obras reforçam o caráter de classe das configurações de saber e práticas referentes à saúde, abordadas a partir de determinações externas - a estrutura sócio-política e econômica, relacionadas com a produção de mais valia e a reprodução da força de trabalho. Esta prática passa a ser analisada também enquanto um Processo deTrabalho, cujos Meios de Trabalho são identificados pela autora como Mercadorias produzidas externamente à medicina, mas consumidas através dela. Estas indicações analíticas 
contribuíram para o desenvolvimento de investigações sobre o processo de trabalho em saúde, que se tornou inclusive uma área temática de estudo no campo da Saúde Coletiva (Donnangelo \& Pereira, 1976).

Há, de forma marcante, uma associação direta entre prática médica liberal, medicalizada e curativista e dominação de classe, aliada à tendência de conferir conotação negativa à própria categoria médica, cujos interesses favorecem os da classe dominante ou se articulam com eles (Donnangelo \& Pereira, 1976).

\section{O "Corpo Social"}

Quando Donnangelo e Pereira se propõem a analisar a prática médica a partir de seu âmbito interno, ressaltando que nem todos os elementos que a constituem são estruturados fora dela, tomam como problemática de estudo o corpo, objeto desta prática. Destacam fundamentalmente sua dimensão social, um corpo que é normatizado social mente e que é antes de tudo Agente de Trabalho (Donnangelo \& Pereira, 1976). O corpo objeto da prática médica não é visto como um corpo sujeito, mas como um corpo que tem sua positividade na significação social que lhe é atribuída. O âmbito biológico particular é redimensionado para o plano coletivo, transposto de um "corpo biológico" para um "corpo social". Tanto médicos como pacientes são analisados a partir da inserção em uma dada estrutura de classe, que identifica a classe médica com os interesses das classes dominantes e a clientela e os pacientes com os interesses das classes trabal hadoras.

A dominação que se exerce no âmbito da relação médico/paciente, enquanto indivíduos que interagem, não é enfatizada nesta produção. Neste sentido, Braga \& Paula, inspirados por certo em Boltanski, indicam que o poder de influência da corporação médica tem uma fundamentação que não é essencialmente econômica, mas baseia-se no controle que detém sobre um saber específico (Braga \& Paula, 1986).

Constata-se que a sociedade civil é reduzida aos agentes sociais identificados basicamente a partir de sua inserção na estrutura econômica de produção, circunscrita, portanto, aos interesses de classe. Como exceção, podemos identificar, além das classes sociais, outros atores como a burocracia e a classe médica (Luz, 1986). É interessante notar inclusive que o termo utilizado por alguns autores, ao referirem-se à relação entre Estado e Sociedade Civil é o termo Estado-classes sociais (Donnangelo \& Pereira, 1976; Oliveira \& Teixeira, 1989).

\section{A reintrodução do conceito de saúde}

Concomitante com a análise crítica da prática médica curativista, reintroduz-se a positividade do conceito de Saúde, excluído da medicina e de sua própria prática, centrada na negatividade da doença. A saúde é recuperada enquanto uma questão política, o que confere uma extensão ao conceito, e faz com que os fatores referentes às condições de vida progressivamente assumam centralidade na sua definição. Esta problematização entre condições de vida e saúde já presente no âmbito da própria Saúde Pública é reforçada pela Saúde Coletiva. Embora a extensão do conceito tenha um impacto político importante, ressaltam-se os riscos de torná-lo demasiadamente amplo, a ponto de ser diluído diante dos problemas que os "tempos modernos" trazem para a vida do cidadão (Braga \& Paula, 1986:37).

Esta concepção ampliada, crucial para a legitimidade das ciências sociais na saúde, no entanto, fortalece em especial a área das políticas de saúde enquanto campo temático e de intervenção. A compreensão da saúde desvinculada do âmbito exclusivamente biológico potencializa a consolidação da medicina enquanto uma questão de política pública (Donnangelo, 1983). Se num primeiro momento a produção acadêmica fundamentada no pressuposto da determinação social do processo saúde-doença esmiuça os fatores econômicos, políticos, ideológicos determinantes deste processo, num segundo momento os pensadores do campo mobilizam-se, inspirados nestas análises, em torno de proposições de ordem prática que possi bilitem a alteração destes determinantes sociais e, portanto, a formulação de propostas e estratégias contra-hegemônicas.

\section{O impacto da Reforma Sanitária na produção científica}

O avanço progressivo (lento e gradual, como se dizia na época) rumo à democratização do sistema político no país, tendo como marco de transição a “Nova República” em 1986, deflagra uma série de transformações com reflexos na produção teórica. No campo da Saúde Coletiva, a temática de oposição ao autoritarismo e de crítica ao sistema de saúde vigente abre espaço para um conjunto de mobilizações e lutas pela implantação do projeto denominado de “Reforma Sanitária". Constitui-se um movimento político em torno da necessária e urgente remodelação do sistema de atenção à saúde introduzindo ao mesmo tempo a ques- 
tão da saúde enquanto um direito de cidadania. Um dos méritos do projeto reformista é ter conseguido aglutinar uma diversidade de atores, formando uma ampla coalizão política em torno dos mesmos princípios que sustentavam a criação do Sistema Único de Saúde.

O processo de redemocratização possibilita a distinção de questões que se confundiam mais facilmente por ocasião da constituição do campo, basicamente a relação entre prática política e produção teórica.

Com o advento da nova república, a temática das políticas sociais adquire um espaço significativo na agenda de governo, sendo a problemática da saúde incluída na famosa dívida social deixada pela regime autoritário. Simultaneamente intensifica-se o debate político em torno do padrão de proteção social mais adequado e conveniente a uma sociedade periférica mas em rápido processo de democratização. A conjuntura democrática provoca diversos impactos na produção teórica do campo da saúde coletiva, complexificando a relação entre sistema político e sistema de saúde. Imprime-se um novo caráter às análises de viés político, já que não é mais possível buscar determinantes do processo político nas estruturas econômicas. A permanência de determinados traços do autoritarismo impõe modificações também no nível das análises teóricas, deixando em evidência a importância de categorias como direitos, cidadania e democracia (Sorj, 1989; Vianna \& Silva,1989).

De um modo geral, podemos identificar na trajetória desta produção dois movimentos centrais em relação à conjuntura anterior. $\mathrm{O}$ primeiro refere-se a um processo de revisão teórico-conceitual dos fundamentos que nortearam até então as análises. Após aproximadamente uma década e meia de obras publicadas, o campo incorpora questões de cunho epistemológico, redefine seus conceitos articuladores e resgata novas dimensões analíticas (Dâmaso,1989). Este processo de construção/ desconstrução se expressa nas várias críticas às "análises histórico-estruturais" ou ao "marxismo de cunho estruturalista" e às "abordagens funcionalistas". Fica claro o reducionismo das análises macro-estruturais e a necessidade de maior refinamento conceitual e metodológico, visando uma aproximação mais analítica e menos marcadamente militante. Multiplicam-se as investigações empíricas e o cuidado na delimitação dos objetos e da metodologia empregada, no sentido de desvendar a dinâmica das relações sociais cotidianas e a diversidade de interesses próprios de uma sociedade civil em acelerado processo de complexificação. Procu- ra-se compreender o nível local dos serviços de saúde em sua relação com o cotidiano de vida da população usuária. A centralidade antes conferida à temática do Estado dá lugar a um deslocamento de foco para a relação estado/ sociedade (Costa et al., 1989; Campos, 1991; Conh et al., 1991).

Algumas análises privilegiam outros parâmetros como os modelos de desenvol vimento nacionais, a ordem política, os regimes políticos, as instâncias institucionais e os sistemas de representação de interesses. Neste sentido, destacam a rede de relações que se estabelecem no próprio aparato burocrático do governo, bem como o "formato político" de gestão das políticas sociais, elucidando os processos de formulação e implementação das políticas públicas, que têm o Estado como centro de decisões (Teixeira, 1989:23).

\section{A inclusão de novas categorias analíticas}

Este movimento deu lugar à utilização de categorias até então pouco presentes na literatura do campo, como cotidiano e representação social (Borges \& Atiê, 1989; Valla \& Siqueira, 1989; Stotz \& Neto,1989; M inayo \& Souza, 1989; Jacobi, 1989; Conh et al., 1991), acompanhada da utilização de abordagens metodológicas pouco comuns na produção, como a aproximação com o enfoque da psicanálise e da técnica da Pesquisa Participante (Minayo \& Souza, 1989), já presente em obra referida ao período anterior (Luz, 1986; Borges \& Atiê, 1989). Questões como os valores culturais da população usuária e sua influência na concepção de saúde/ doença também são abordadas nesta produção recente apontando especificidades que se diluíram nas análises estruturais de cunho marxista (Jacobi, 1989; Minayo \& Souza, 1989).

Uma temática que progressivamente ganha espaço gira em torno da Gerência e Administração em nível local dos Serviços (Campos, 1991). Isto reflete, em parte, uma tendência da literatura para incorporar questões concretas de cunho técnico-operacional ao setor saúde, pensando a Reforma Sanitária também a partir de fatores referentes ao processo de programação e gerência da rede de serviços.

Renasce a possibilidade de um diálogo mais estreito e em outras bases entre a Saúde Coletiva e a clínica, entre o social e o biológico. A Saúde Coletiva havia deixado de lado a análise da especificidade da clínica dentro do conjunto das práticas em saúde e, como parte de um mesmo movimento, excluiu tanto a prática médica quanto os próprios médicos, sujeitos 
políticos fundamentais na estruturação do sistema (Campos, 1991).

Essas abordagens trazem questões importantes no nível operacional dos serviços e que antes não encontravam espaço em análises macro-estruturais. Convém ressaltar ainda a temática do processo de trabalho em saúde e do chamado corporativismo profissional (Campos, 1991). Além disso, a dimensão pedagógica-educativa da relação médico paciente situada na rede de micro-poderes que se estabelece no interior dos serviços de saúde constitui outra abordagem inovadora do período (Ramos et al., 1989).

Estas modificações no plano teórico relacionam-se em parte ao movimento mais amplo de redemocratização da sociedade brasileira, em um processo onde a sociedade civil é revitalizada e o lugar da ação política organizada é redefinido. Nesse sentido, destacam-se questões como participação popular/ controle social, movimentos sociais em saúde democratização dos processos decisórios, mecanismos de representação de interesses.

A noção de interesse ganha novo significado. Diversificam-se os tipos de interesses e os grupos considerados como influentes nos processos de formulação e implementação de políticas públicas. Alguns autores chegam a considerar o próprio indivíduo enquanto sujeito político, inclusive em sua dimensão subjetiva (Borges \& Atiê, 1989; Minayo \& Souza, 1989; Campos, 1991). A valorização do papel dos atores sociais relaciona-se às possibilidades criadas pela Reforma Sanitária. O processo de restruturação do Sistema de Saúde impunha uma base social ampla, com a incorporação orgânica de diversos partidos, sindicatos, enfim, da chamada sociedade civil organizada e, inclusive, assumindo reivindicações concretas da própria população usuária (Bodstein \& Fonseca, 1989; Borges \& Atiê, 1989; Minayo \& Souza, 1989; Valla \& Siqueira, 1989; Campos, 1991; Conh et al., 1991).

É importante ressaltar que este movimento reflete, em grande parte, não só uma redefinição radical do cenário político, como um processo que ocorre no âmbito das ciências políticas e da sociologia em torno da chamada crise dos paradigmas das ciências sociais e da crítica às análises macroestruturais e à diluição do papel dos sujeitos e dos atores sociais (Touraine,1984 apud Ianni, 1990:91). Neste sentido, podemos considerar que o campo da Saúde Coletiva mesmo que permeável à influência direta da conjuntura política caminha para um amadurecimento da sua relação com as disciplinas próprias das Ciências Sociais.

\section{Saúde como direito de cidadania}

Num contexto de redemocratização acelerada que norteia a Reforma Sanitária onde Saúde é concebida enquanto dever do Estado e direito de cidadania, a categoria Cidadão é reintroduzida e ganha novo status teórico.

Este conceito no entanto adquire dimensões distintas de acordo com as análises traduzidas na figura do cidadão usuário do sistema de saúde, dos consumidores desses serviços (Cohn et al., 1991; Costa et al., 1989) ou de seus produtores, os profissionais de saúde, seus projetos políticos e sua influência na estruturação/ reestruturação do Sistema (Campos, 1991). Outras análises, por sua vez, enfatizam a figura do Cidadão Político. Isto se deve em parte ao próprio instrumental analítico que situa preferencialmente o plano dos processos estruturais de formulação e implementação de políticas ou a dimensão dos serviços e seus usuários.

É forçoso reconhecer o avanço imprimido pela introdução do conceito de cidadania, uma vez que, dentro de uma análise marxista ortodoxa esta categoria é concebida como uma mistificação burguesa. Há até mesmo uma defesa da propriedade analítica deste conceito (Teixeira, 1989).

A abordagem da questão da cidadania avança quando entendida enquanto universalização de direitos sociais construída a partir das reivindicações concretas dos segmentos desfavorecidos da sociedade. Trata-se de uma concepção de direito enquanto al go a ser constituído a partir da ação política, onde a ênfase recai sobre a dimensão concreta deste fenômeno sem abordá-la em momento al gum como uma abstração, ideologia ou mistificação (Cohn et al., 1991).

A introdução das categorias de cidadania e de democracia redefine a temática do Controle Social e do Direito. A perspectiva agora se torna propositiva, ou seja, o usuário por ser cidadão tem o direito de controlar o Estado e não o contrário (Bodstein \& Fonseca, 1989; Valla \& Siqueira, 1989). Algumas abordagens concentram-se na análise comparativa entre o que é instituído como "direito" e o que de fato a população recebe enquanto "serviço", em termos de qualidade e acessibilidade (Cohn,1989). Outros autores já expressam uma preocupação em pensar caminhos e traçar proposições de ordem prática para que estes ganhos constitucionais realmente sejam efetivados (Teixeira,1989; Campos,1991). Essa distinção de enfoques sinaliza uma polêmica, que se desenvolve no interior do Campo em torno da articulação entre questões de ordem mais especificamente explicativa e de prática político - partidária. 


\section{Atuação política e produção científica}

Os limites e possibilidades da articulação entre prática política e produção acadêmica são problematizados na produção mais recente revelando, sem dúvida, um amadurecimento do Campo. Esta relação por vezes é vista como bastante positiva para o ensino e a pesquisa em Saúde Coletiva por possibilitar a transcendência dos limites estritamente disciplinares e de intervenção mais direta na realidade. É exatamente esta possibilidade que parece apaixonar alguns pesquisadores, produzindo uma certa adesão ativa, com o poder de atrair grupos de profissionais, criando a figura do "intelectual comprometido".

Essa articulação estreita entre teoria e ação política atravessa todo o campo e a sua produção, culminando na construção de um projeto contra-hegemônico definido pelos princípios da Reforma Sanitária. A preocupação em elaborar proposições estratégicas para o setor no sentido de garantir condições de viabilidade para a Reforma Sanitária é contundente. Neste processo, a visão estratégica da política setorial parece substituir a perspectiva analítica, uma vez que a intenção central é traçar os contornos de um modelo ideal (Campos, 1991).

Nesta conjuntura o debate gira em torno da formulação de estratégias de transformação setorial com vistas à implantação de um determinado projeto político ou de construção de um novo bloco histórico (um conceito que expressa a influência gramsciana na literatura política Latino-Americana) (Gallo \& Nascimento, 1989; Campos, 1991; Coutinho \& Nogueira, 1988).

O pensamento estratégico, que tem em Mário Testa e Carlos Matus seus principais expoentes, conquista um lugar significativo no campo da Saúde Coletiva neste período, uma vez que o que está em jogo é a ocupação paulatina de espaços políticos no interior do "apareIho de Estado" (Matus, 1982; 1987; Testa, 1981).

Ainda que seja por vezes enriquecedora e tenha possibilitado ganhos significativos para o setor, a proximidade entre prática política e produção teórica vem sendo questionada pelo próprio campo. No relato de alguns autores “uma vinculação mecânica entre um e outro faz com que se perca tanto da prática política quanto da construção do conhecimento. É preciso que setenha certas 'crises' para que setenha um pouco mais de autonomia [...]" (Burlandy, 1993: 387).

Este debate aponta para a problematização do papel do Cientista Social de quem devemos esperar "menos referências para a ação do que elementos para reflexão, devendo el e preferir a incerteza ea perplexidade à tranqüilidade das soluções que, quer por incoerência ou contrafatualidade, sabe que são lacunares, ou ainda inadequadas e/ou tendenciosas."(Cohn et al., 1991:7).

As críticas à instrumentalização das ciências sociais partem dos próprios cientistas sociais que indicam a necessidade de resgatar o caráter originário de sua função, ressaltando o limite tênue entre a figura do intelectual comprometido que consegue articular teoria e prática e a relação por demais estreita entre análises teóricas e projetos políticos (Sorj, 1989:159).

Foi diante de um contexto político marcado por regimes ditatoriais que o pensamento social na América Latina tendeu para uma "sociologia do desejo", na medida em que os autores “[...] projetaram o desejo sobre a própria realidade social. Em vez de aceitar as dificuldades ou a inviabilidade da transformação social revolucionária, exageraram a importância relativa deagentes, processos e instituições sociais, ao mesmo tempo em que desconheceram e ignoraram teoricamenteo conjunto deforças e processos sociais que atuam em direção contrária a desejada" (Sorj, 1989:157). Esta oposição frontal repercute também na própria concepção de Sociedade Civil, gerando por vezes, uma visão extremamente positiva/romântica dos fenômenos que emanam do âmbito societal, numa falsa suposição de que as distorções estejam concentradas fundamentalmente no nível do poder do Estado (Sorj, 1989).

Esta tendência a uma maior distinção entre os fatores referentes ao campo da política e questões de ordem especificamente analíticas, intensifica-se durante o processo de redemocratização. Neste contexto, suavizam-se pressões advindas da luta político-partidária contra a ordem autoritária, propiciando o aprofundamento e a revisão dos esquemas analíticos consagrados no campo. Assim a conjuntura acaba por provocar o alargamento do debate e a saudável pluralidade de abordagens teórico-conceituais vis-à-vis o aparecimento de novos objetos de reflexão. Cabe considerar que a redemocratização e a necessidade de formular projetos políticos alternativos, paradoxalmente, revitalizam a influência de uma certa perspectiva voluntarista, comum ao pensamento marxista na América Latina. 


\section{A problemática do Estado} e das políticas sociais

Consolida-se na literatura do campo uma concepção ampliada do Estado, já indicada no período anterior (Luz, 1986). O Estado é visto enquanto arena de luta, possibilitando uma compreensão estratégica das políticas de saúde, na medida em que delimitam um espaço de construção de projetos contra-hegemônicos. Não há mais lugar, na produção recente, para uma concepção mecânica das políticas sociais enfocadas como instrumento de acumulação de capital. Os próprios princípios defendidos pelo movimento da Reforma Sanitária, como uma maior presença do Estado no setor saúde, não teriam sentido diante de uma concepção restrita que reforça o aspecto funcional das ações estatais e das políticas públicas para o capitalismo.

Transformações ocorridas no cenário internacional nas últimas décadas ajudaram a refinar o quadro explicativo nas abordagens das políticas públicas. A investida neoliberal - centrada na crítica sobre os efeitos perversos do sistema de proteção social e na necessidade de corte de gastos públicos-, demonstra, inclusive para a própria esquerda, que as políticas sociais e o chamado Welfare State, nunca foram exatamente funcionais ao mercado, como as análises de inspiração marxistas faziam crer. Essas políticas assumem inclusive importância significativa no contexto das democracias modernas - às voltas com a necessidade de reinvenção de novas formas de solidariedade e de coesão social -, redefinindo o papel do governo, o alcance da intervenção pública e a própria agenda social (Bodstein, 1992).

Trata-se, nessa conjuntura, de desconfiar das teorias conspirativas, tão freqüentes no pensamento da esquerda, que se não identificavam mais nas políticas governamentais a marca do processo de acumulação de capital, compreendiam tais políticas ainda como expressão direta de interesses de classe.

Apesar da relativa complexidade do quadro conceitual que embasou a contribuição das ciências sociais para a produção científica em Saúde Coletiva, é necessário reconhecer a influência do estruturalismo e do determinismo, como apontado inicialmente. O processo de reestruturação e de constante reflexão teóricoconceitual do campo, no sentido de ampliar o escopo explicativo necessário à complexidade de seu objeto de estudo, permaneceu, em grande parte, atrelado aos propósitos da denúncia e das estratégias políticas da militância e do pensamento de esquerda.
Na produção em torno do Estado e das políticas de saúde este processo foi mais visível na medida em que havia uma sintonia fina entre o referencial do materialismo histórico e a busca de macro-determinantes para a caracterização do Estado, do processo decisório, das políticas públicas e das ações governamentais de âmbito social. Neste movimento, deixava-se delado atores e sujeitos políticos que não podem ser definidos estruturalmente, mas a partir de interesses e identidades que se constituem através da diversidade de relações, papéis e identidades políticas (Bodstein, 1992: 147).

\section{Reflexões atuais}

Uma das questões centrais que conferem identidade à reflexão teórica das ciências sociais dentro do Campo da Saúde Coletiva no período inicial de sua constituição, diz respeito à análise crítica do processo de medicalização (Donnangelo \& Pereira, 1976:30-38). Conforme definição de Donnangelo \& Pereira, esse processo se refere ao movimento secular de expansão de um conjunto de saberes e práticas e de criação de instituições médico-sanitárias indispensáveis ao próprio desenvolvimento das sociedades capitalistas. A medicalização foi entendida assim a partir, quer da férrea lógica da racionalidade científica moderna e da exploração da mais valia, quer a partir de sua manifestação através de formas sutis de dominação e de disciplinarização dos corpos, como mostrou Foucault.

Hoje em dia, parece importante reconhecer, que estes dois caminhos - mesmo que moldando vertentes analíticas distintas e extremamente importantes dentro das ciências sociais nas décadas de 70 e 80 - comportam uma identificação mecânica e, muitas vezes, simplificadora da relação entre conhecimento e poder, coerente com uma concepção unilateral sobre a natureza da sociedade moderna. A radicalidade dessa concepção reside na negação/ superação da sociedade capitalista e das instituições liberais democráticas como um todo. $\mathrm{O}$ argumento levado às últimas conseqüências acaba por atribuir ao avanço técnico-científico - e a qualquer instituição moderna, mesmo aquelas constituídas a partir de um longo e dramático processo de ampliação da democracia e dos direitos - a marca da racionalidade instrumental, da exploração econômica capitalista e da sujeição dos indivíduos e corpos à disciplina da produção e do trabalho alienado. Dessa forma, a concepção de ciência, e da pró- 
pria ordem social moderna, é reduzida a formas variadas de regulamentação sistêmicas e de mistificações ideológicas, deixando claro o viés determinista comum às duas abordagens.

Sem dúvida, a vertente foucaultiana trouxe impulsos inovadores ao conjunto das ciências sociais nos anos 70, sendo rapidamente incorporada ao campo da saúde coletiva entre nós. Grande parte de seu sucesso pode ser atribuído à ênfase nos discursos, práticas e instituições, aparentemente mais neutros e distantes da racionalidade técnico-instrumental - e, até então desprezados pelas análises de viés marxista-, como práticas poderosas ainda que sutis, de controle do corpo e de aprisionamento dos indivíduos à ordem dominante.

Nessa medida, podemos dizer que este campo científico estruturou-se basicamente em torno da análise crítica e da denúncia contundente à ordem capitalista com sua racionalidade instrumental e, no caso específico, em oposição cerrada às políticas médico-sanitárias, ao sistema de saúde privado e assistencialista, ao conhecimento médico dominante, enfim ao processo de medicalização como um todo. Convém observar que através desse esquema explicativo, tanto o conhecimento médicosanitário como as práticas e políticas de saúde são estruturalmente determinados e, portanto, compreendidos sem qualquer ambigüidade: reflexo ou conseqüência prevista da influência crescente do desenvolvimento do sistema capitalista.

É exatamente essa perspectiva unilateral e reducionista, onde não se leva em conta a complexidade da sociedade moderna e a heterogeneidade crescente da vida social, que vem sendo criticada no âmbito das ciências sociais contemporâneas por autores como Castoriadis (1986); Boudon (1995); Guiddens (1989), entre outros.

A crise que atinge diretamente a sociologia, e também o conjunto das ciências sociais no cenário do fim das utopias, traduz-se, entre outros aspectos, pela falência dos esquemas explicativos globais, que acabavam por enquadrar processos, identidades e atores sociais dentro de uma única e mesma lógica sistêmica. O resultado é o empobrecimento da dinâmica das relações sociais, tão brilhantemente defendida pelos fundadores da teoria sociológica. Deixa-se de lado, uma dimensão crucial do conhecimento sociológico que diz respeito exatamente ao fenômeno da relativização.

Como mostra Da Matta, "A matéria-prima das "ciências sociais", (...) são eventos com determinações complicadas e que podem ocorrer em ambi entes diferenciados tendo, por causa disso, a possibilidade de mudar seu significado de acordo com o ator, as rel ações existentes num determinado momento e, ainda, com a sua posição numa cadei a de eventos anteriores e posteriores" (Da Matta, 1991:18-19)

Trata-se de mostrar, por outra perspectiva, que a sociologia, em particular, encontra-se sintonizada com a modernidade “(...) justamente por representar a consciência de um mundo em que os val ores têm si do radi cal mente relativizados" (Berger, 1995:59). Convém perceber “(...) quea percepção soci ol ógi ca é refratária a ideol ogias revolucionárias, não porque traga consi go al guma espéci e de preconcei to conservador, mas porque el a enxerga não só através das ilusões do status quo atual como também através das expectativas ilu sórias concernentes a possíveis futuros, sendo tais expectativas o costumei ro alimento espiritual dos revolucionários" (Berger, 1995:58).

Se o quadro conceitual presente na Saúde Coletiva é, portanto, dotado de complexidade irredutível a um determinado viés analítico tal como os autores clássicos do período de formação do campo já destacavam -, esta heterogeneidade teórica revela-se hoje mais aparente do que real. Apesar da produção caracterizar-se "pela ênfase em distintos obj etos e em distintos campos de saber, por variações temáticas metodológi cas da análise, por distintas opções sobre modelos experimentais" (Donnangelo, 1983:27), encontra-se essencialmente influenciada pela perspectiva objetivista nas ciências sociais. Hoje em dia, é absolutamente necessário reconhecer dentro do campo da saúde coletiva os inconvenientes e limites dessa perspectiva mesmo quando se trata da análise do Estado e das políticas sociais (Bodstein, 1992).

Resta observar que os impulsos inovadores e criativos vindos da chamada crise dos paradigmas nas ciências sociais só muito lentamente vêm sendo incorporados ao campo. Tais impulsos têm o mérito de provocar uma rejeição quase completa daquilo que Castoriadis tão bem denominou de "teoria fechada" (Castoriadis, 1986:86), no sentido da crítica às abordagens que ao optarem por análises mais estruturais, acabam por excluir o papel das contingências e dos efeitos mais ou menos imprevisíveis da ação humana sobre todo sistema sócio-cultural.

Grande parte da produção teórica em torno das políticas de saúde no Brasil e da chamada reforma sanitária, acabou por consolidar um pensamento militante necessário, por certo, naquela conjuntura, mas de excasso vaIor explicativo. No caso, trata-se de chamar a atenção para os impactos negativos e para os 
efeitos perversos de determinados princípios técnico-normativos ou de determinadas bandeiras do movimento sanitário quando implementados dentro de um cenário político concreto.

Na discussão teórica referente à contribuição da sociologia para a temática da saúde, a questão gira em torno da necessidade de se considerar mais seriamente a crítica em torno do reduzido poder explicativo de análises que compreendem processos e relações sócio-culturais como exterioridades. Com isso, recai-se numa simplificação e num empobrecimento da contribuição específica das ciências sociais, que deve sempre incluir a diversi dade de racionalidades, intenções e significados presentes na ação humana (Boudon, 1995:45). Os indivíduos/ sujeitos dentro da interpretação objetivista, acabam por perder sua capacidade de ação/ reação diante da pluralidade de referências culturais e da diversidade de contextos de interação típicos da sociedade moderna.

Para a reflexão atual do campo é necessário que se afirme a importância da antropologia médica, por um lado, e, por outro, da economia em saúde. Sem dúvida, inauguram vertentes metodológicas específicas dentro das ciências sociais em saúde, cujo balanço ainda está por ser feito.

Finalmente, é necessário não se perder de vista nessa trajetória a imaginação sociológica e política, isto é, nossa capacidade de inventar novos sentidos para a vida em sociedade. É preciso ainda investir em novos caminhos teórico-metodológicos, reformulando nossos objetos de reflexão e nosso foco de análise. A vontade radical de transformar a sociedade impõe maior lucidez analítica e consciência da transição paradigmática que vivem as ciências sociais hoje, como enfatiza Boaventura de Souza Santos (Santos, 1995:38). De acordo com o autor, os impasses advindos da crise simultânea dos paradigmas da regulação (da capacidade de regulação social através de mecanismos institucionais) e da emancipação (das potencialidades da ação política das classes na transformação social) impõem novas utopias. O desafio dos novos tempos está na compreensão (weberianamente falando) da tendência, irreversível ao que parece, de consolidação de uma sociedade crescentemente individual ista porém, com espaço para a preservação da autonomia dos sujeitos envolvidos em distintos projetos de autocriação e de formação de novas identidades sociais. Portanto, a modernidade capitalista, vis-à-vis aos riscos do individualismo crescente, introduz novas utopias: da sociedade auto-instituinte, da cidadania universal, da ampliação dos direitos e até mesmo do direito à diferença, no sentido da vontade crescente de convivência com a pluralidade. Sem dúvida, tais impulsos devem redimensionar e ampliar o campo de reflexão das ciências sociais em saúde.

\section{Referências}

ALMEIDA, C. \& BURLANDY, L., 1991. A Opção Estruturalista em Saúde Coletiva, Rio de Janeiro: Escola Nacional de Saúde Pública, Fundação Oswaldo Cruz.(mimeo.)

BERGER, P., 1995. Perspectivas Sociológicas (Uma Visão Humanista). 14a ed., Petrópolis: Vozes.

BIRMAN, J., 1991. A physis da saúde coletiva. Physis, 1:6-11.

BODSTEIN, R. C. A., 1992. Ciências sociais e saúde coletiva: novas questões, novas abordagens. $\mathrm{Ca}$ dernos de Saúde Pública, 8:140-148.

BODSTEIN, R. C. \& FONSECA, C., 1989. Desafio da reforma sanitária: consolidação de uma estrutura permanente de serviços básicos de saúde In: Demandas Populares, Políticas Públicas e Saúde (N. R. Costa, C. S. Minayo, C. L. Ramos \& E. N. Stotz, orgs.), Vol I, pp. 67-90, Rio de Janeiro: Vozes.
BORGES, S. M. N. \& ATIÊ, E., 1989. Vida de mulher: estratégias de sobrevivência no cotidiano In: De mandas Populares, Políticas Públicas e Saúde. (N. R. Costa, C. S. Minayo, C. L. Ramos \& E. N. Stotz, orgs.), Vol II, pp. 165-184, Rio de Janeiro: Vozes.

BOUDON, R., 1995. Tratado de Sociologia. Rio de Janeiro: Jorge Zahar Editora.

BOURDIEU, P., 1976. Le champ scientifique. Actes de la Rechercheen Sciences Sociales, 2/ 3: 88-104.

BRAGA, J. \& PAULA, S. G., 1986. Saúde e Previdência: Estudos de Política Social. 2a ed., São Paulo: Hucitec.

BURLANDY, L., 1993. Saúde Coletiva: Uma Trajetória em Questão. Refletindo sobre a Produção Científica no Campo das Políticas de Saúde. Dissertação de Mestrado, Rio de Janeiro: Escola Nacional de Saúde Pública, Fundação Oswaldo Cruz. 
CAMPOS, G. W. S., 1991. A Saúde Pública ea Defesa da Vida. São Paulo: Hucitec.

CANESQUI, A. M., 1995. Dilemas e Desafios das Ciências Sociais na SaúdeColetiva. São Paulo: Hucitec/ Rio de Janeiro: Abrasco

CASTORIADIS, C., 1986. A Instituição Imaginária da Sociedade. 2a ed., Rio de Janeiro: Paz eTerra.

COHN, A., 1989. Caminhos da Reforma Sanitária. Lua Nova, 19: 123-140.

COHN, A.; NUNES,.E.; JACOBI, P. \& KARSH, U. S., 1991. A Saúde como Direito e como Serviço. São Paulo: Cortez.

COSTA, D. C. \& COSTA, N. R. 1990. Teoria do conhecimento e epidemiologia : um convite a leitura de John Snow. In: Epidemiologia Teoria e Objeto (D. C. Costa, org.), pp. 167-201, São Paulo: Hucitec/ Rio de Janeiro: Abrasco.

COSTA, N. R.; MINAYO C. S.; RAM OS C. L. \& STOTZ, E. N., orgs., 1989. Demandas Populares, Políticas Públicas eSaúde. Vol. II, Rio de Janeiro: Vozes.

COUTINHO, C. N. \& NOGUEIRA, M. A., 1988. Gramsci ea América Latina. Rio de Janeiro: Paz eTerra.

DÂM ASO, R., 1989. Saber e práxis na reforma sanitária avaliação da prática científica no movimento sanitário. In: Reforma Sanitária em Busca de uma Teoria (S. Teixeira, org.), pp. 61-90, Rio de Janeiro: Abrasco.

DA M ATTA, R., 1991. Relativizando (Uma introdução à Antropologia Social). 3a ed., Rio de Janeiro: Rocco.

DONNANGELO, M. C. F, 1983. A pesquisa na área de saúde coletiva no Brasil: a década de 70 . Ensino da Saúde Pública e Medicina Preventiva e Social no Brasil. Rio de Janeiro: Abrasco.

DONNANGELO, M. C. F. \& PEREIRA, L., 1976. Saúdee Sociedade. São Paulo: Duas Cidades.

FIORI, J. L., 1978. Introdução. In: Saúdee Medicina no Brasil (R. Guimarães, org.), pp.17-27, Rio de Janeiro: Graal.

GALLO, E. \& NASCIMENTO, P. C., 1989. Hegemonia: bloco histórico e movimento sanitário. In: Reforma Sanitária em Busca de uma Teoria (S. M. F. Teixeira, org.), pp. 91-118, Rio de Janeiro: Abrasco.

GARCIA, J. C., 1989. As ciências sociais em medicina. In: Pensamento Social em Saúdena América Latina (E. D. Nunes, org.), pp.51-67, São Paulo: Cortez.

GUIDDENS, A., 1989. A Constituição da Sociedade. São Paulo: Martins Fontes.

IANNI, O., 1990. A crise de paradigmas na sociologia. Revista Brasileira deCiências Sociais, 13:90-100.

JACOBI, P. R., 1989. Movimentos sociais e Estado: efeitos político-institucionais da ação coletiva. In: Demandas Populares, Políticas Públicas e Saúde (N. R. Costa, C. S. Minayo, C. L. Ramos \& E. N. Stotz, orgs.), Vol. II, pp. 13-35, Rio de Janeiro: Vozes.

LUZ, M. T., 1986. As Institui ções Médicas no Brasil: Instituição e Estratégia de Hegemonia. 3a ed. Rio de Janeiro: Graal.

MATUS, C., 1982. Política y Plan. Caracas: Iveplan.

MATUS, C., 1987. Adios Señor Presidente. Caracas: Pomaire.

MERCER, H., 1985. As contribuições da sociologia à pesquisa em saúde. In: As Ciências Sociais em Saúdena América Latina: Tendências e Perspectivas ( $E$. Nunes, org.), pp. 221-232, Brasília: OPAS (Organização Panamericana da Saúde).
MINAYO, M. C. S. \& SOUZA, H. O., 1989. Na dor do corpo, o grito da vida. In: Demandas Populares, Políticas Públicas e Saúde (N. R. Costa, C. S. Minayo, C. L. Ramos \& E. N. Stotz, orgs.), Vol. II, pp. 75-101, Rio de Janeiro: Vozes.

NOVAES, R. L., 1988. Reflexões sobre o Campo da Saúde Coletiva. São Paulo. Instituto de Medicina Social, Universidade de São Paulo. (mimeo.)

NUNES, E. D., 1985. Tendências e perspectivas das pesquisas em ciências sociais em saúde na América Latina: uma visão geral. In: As Ciências Sociais em Saúde na América Latina: Tendências e Perspectivas (E. Nunes, org.), pp. 29-79, Brasília: OPAS (Organização Panamericana de Saúde).

OLIVEIRA, J. A. \& TEIXEIRA, S. M. F., 1989. (IM) Previdência Social: 60 Anos de História da Previdência no Brasil. 2a Ed., Petrópolis: Vozes.

RAM OS, C. L.; MELO, J. A. C. \& SOARES, J. C. R., 1989. Quem educa quem? Repensando a relação médico - paciente. In: Demandas Populares, Políticas Públicas e Saúde. (N. R. Costa, C. S. Minayo, C. L. Ramos \& E. N. Stotz, orgs.), pp. 145-164, Rio de Janeiro: Vozes.

RIBEIRO, P. T., 1991. A Instituição do Campo Científico da Saúde Coletiva no Brasil: 1975/1978. Dissertação de Mestrado, Rio de Janeiro: Escola Nacional de Saúde Pública, Fundação Oswaldo Cruz.

SANTOS, B. S., 1995. Pela Mão de Alice (O Social eo Político na Pós-Modernidade). São Paulo: Cortez.

SORJ, B., 1989. Crise e horizonte das ciências sociais na América Latina. Novos Estudos, 23:154- 162.

STOTZ, E. N. \& NETO, O. C., 1989. Processo de trabaIho e saúde. O caso dos trabal hadores em curtume. In: Demandas Populares, Políticas Públicase Saúde. (N. R. Costa, C. S. Minayo, C. L. Ramos \& E. N. Stotz, orgs.), pp. 36-73, Rio de Janeiro: Vozes.

TEIXEIRA, S. M. F. 1985. As ciências Sociais em Saúde no Brasil. In: As Ciências Sociais em Saúde na América Latina - Tendências e Perspectivas. (E. Nunes, org.), pp. 87-110, Brasília: OPAS (organização Panamericana da Saúde).

TEIXEIRA, S. M. F., 1989. Reforma Sanitária em Busca de uma Teoria. Rio de Janeiro: Abrasco.

TEIXEIRA, S. M. F., 1992. Saúde Coletiva? Questionando a Oni potência do Social. Rio de Janeiro: Relume Dumará.

TESTA, M., 1981. Planificación Estratégica en el Sector Salud. Caracas: Cendes.

VALLA, V. V. \& SIQUEIRA, S. A. V. 1989. O Centro Municipal de Saúde e a participação popular. In: De mandas Populares, Políticas Públicas e Saúde (N. R. Costa, C. S. Minayo, C. L. Ramos \& E. N. Stotz, orgs.), pp. 91-116, Rio de Janeiro: Vozes.

VIANNA, M. L. W. \& SILVA, B. A., 1989. Interpretação e avaliação da Política Social no Brasil: uma bibliografia comentada. In: Economia e Desenvolvimento. A Política Social em Tempo de Crise: Articulação Institucional e Descentralização (MPAS/ CEPAL), pp. 111-225, Brasília: CEPAL. 